\title{
Criptógamos do Parque Estadual das Fontes do Ipiranga, São Paulo, SP. Algas, 32: Dinophyceae (famílias Dinococcaceae, Gymnodiniaceae e Hemidiniaceae)
}

\author{
Carlos Eduardo de Mattos Bicudo ${ }^{1}$
}

Recebido: 18.03.2010; aceito: 17.02.2011

\begin{abstract}
Cryptogams of the "Parque Estadual das Fontes do Ipiranga", São Paulo, SP. Algae, 32: Dinophyceae (families Dinococcaceae, Gymnodiniaceae and Hemidiniaceae)). Taxonomic survey of representatives of families Dinococcaceae, Gymnodoniaceae and Hemidiniaceae in the Parque Estadual das Fontes do Ipiranga, São Paulo, Brazil. Five genera (Amphidinium, Dinococcus, Gymnodinium, Hemidinium and Katodinium) and fourteen species (four of Amphidinium, four of Hemidinium, three of Gymnodinium, two of Katodinium and one of Dinococcus) and two varieties that are not the typical of their respective species were identified. Amphidinium kesslitzii Schiller var. kesslitzii, Gymnodinium fuscum (Ehrenberg) Stein and Hemidinium brasiliense C. Bicudo \& Skvortzov occurred in two localities each, whereas all other species in a single locality each.
\end{abstract}

Key words: Amphidinium, Brazil, Dinococcus, dinoflagellates, Gymnodinium, Hemidinium, Katodinium

RESUMO - (Criptógamos do Parque Estadual das Fontes do Ipiranga, São Paulo, SP. Algas. 32: Dinophyceae (famílias Dinococcaceae, Gymnodiniaceae e Hemidiniaceae)). Levantamento florístico dos representantes das famílias Dinococcaceae, Gymnodiniaceae e Hemidiniaceae (Dinophyceae) do Parque Estadual das Fontes do Ipiranga, São Paulo, Brasil. Cinco gêneros (Amphidinium, Dinococcus, Gymnodinium, Hemidinium e Katodinium) e 14 espécies (quatro de Amphidinium, quatro de Hemidinium, três de Gymnodinium, duas de Katodinium e uma de Dinococcus) e duas variedades que não são as típicas de suas respectivas espécies foram identificados. Amphidinium kesslitzii Schiller var. kesslitzii, Gymnodinium fuscum (Ehrenberg) Stein e Hemidinium brasiliense C. Bicudo \& Skvortzov ocorreram em duas localidades cada um, enquanto que as demais apenas em um local.

Palavras-chave: Amphidinium, Brasil, Dinococcus, dinoflagelados, Gymnodinium, Hemidinium, Katodinium

\section{Introdução}

Os representantes tecados das Dinophyceae têm recebido atenção bem maior por parte dos especialistas do que os não-tecados ou cujas tecas são discerníveis só com muita dificuldade. Este fato ocorre em nível mundial e é especialmente verdadeiro quando se trata do conhecimento da flórula de algas do PEFI, Parque Estadual das Fontes do Ipiranga, em São Paulo.

$O$ conhecimento das formas não-tecadas (Dinococcaceae e Gymnodiniaceae) ou com tecas pouco visíveis ao microscópio óptico (Hemidiniaceae) das Dinophyceae do PEFI está contido apenas em três publicações. A primeira é de Bicudo \& Bicudo (1967), que estudaram a composição florística de comunidades flutuantes de algas que surgiram no hidrofitotério do Jardim Botânico de São Paulo e identificaram Amphidinium sp. e Hemidinium nasutum Stein var. tatricum Wołoszyńska. A segunda é de Bicudo \& Skvortzov (1970), onde foram identificados quatro gêneros e 12 espécies da análise de 20 amostras de material coletado em ambientes do Parque Estadual das Fontes do Ipiranga. Cinco dessas espécies (três de Hemidinium e duas de Katodinium) e uma variedade de Amphidinium foram descritas e propostas como novas para a Ciência nesse trabalho. E a terceira é de Bicudo \& Menezes (2006) que fizeram referência à ocorrência de Dinoccoccus bicornis (Wołoszyńska) Fott no hidrofitotério do Jardim Botânico de São Paulo.

1. Instituto de Botânica, Caixa Postal 68041,04045-972, São Paulo, SP, Brasil. cbicudo@terra.com.br 
Bicudo \& Skvortzov (1970) contém descrição detalhada e ilustração de todos os materiais estudados e uma chave artificial para sua identificação, enquanto que Bicudo \& Menezes (2006), por ser uma chave para identificação de gêneros, somente ilustraram o material que estudaram.

O presente trabalho visou a identificar taxonomicamente as Dinococcaceae, Gymnodiniaceae e Hemidiaceae do PEFI, com vistas ao levantamento da ficoflórula do Parque.

\section{Material e métodos}

O presente trabalho foi baseado em material da literatura e em coletas posteriores às publicações acima. Estas coletas foram feitas nos ambientes semilênticos do PEFI, obedecendo à periodicidade de cada trabalho (trabalhos de ecologia), além de outras, esporádicas, realizadas também nos ambientes lóticos do PEFI (trabalhos taxonômicos). Tanto do material já publicado quanto das coletas posteriores há material depositado no Herbário Científico do Estado "Maria Eneyda P. Kauffmann Fidalgo" (SP) do Instituto de Botânica da Secretaria do Meio Ambiente do Estado de São Paulo.

A visualização das plaquetas de Hemidium nasutum var. tatricum foi possível após usar, primeiro, solução aquosa de hipoclorito de sódio a $30 \%$ para descolorir o protoplasma. Depois, impregnou-se a teca com solução aquosa de azul de metileno a $5 \%$ para evidenciar os limites das plaquetas.

Para a fácil localização dos gêneros neste trabalho, eles aparecem relacionados em ordem alfabética crescente. As espécies que só constam da literatura, isto é, que jamais foram reencontradas estão precedidas por um asterisco nas chaves de identificação e no texto.

O sistema de classificação em famílias adotado é o que consta em Popovský \& Pfiester (1990), bem como o foram as circunscrições das famílias e dos gêneros.

\section{Resultados e Discussão}

Os cinco gêneros presentemente identificados para o PEFI têm a seguinte situação sistemática:

\author{
Classe Dinophyceae \\ Subclasse Dinophycidae \\ Ordem Peridiniales \\ Família Gymnodiniaceae \\ Amphidinium \\ Gymnodinium \\ Katodinium \\ Família Hemidiniaceae \\ Hemidinium \\ Ordem Dinococcales \\ Família Dinococcaceae \\ Dinococcus
}

\section{GYMNODINIACEAE}

Esta família inclui indivíduos unicelulares de vida livre, hábito isolado, ativamente móveis na fase vegetativa. A célula é nua, isto é, destituída de parede celular formada por plaquetas de celulose. Envolve, então, o protoplasma um tipo de periplasto flexível, a chamada película. Cromoplastídios usualmente ausentes, mas podem ocorrer até em número de 10 ou mais. A nutrição na família varia entre autotrófica ou holofítica (nas formas pigmentadas) a sapróbica (nas formas despigmentadas).

\section{Amphidinium Claparède \& Lachmann}

Indivíduos livre-natantes, de vida isolada, cuja célula é mais ou menos ovóide em vista ventral (taxonômica) $\mathrm{e}$, em alguns casos, dorsiventralmente achatada. $\mathrm{O}$ cíngulo está situado bastante anteriormente na célula, de modo que o epicone é acentuadamente menor e também mais estreito que o hipocone. $\mathrm{O}$ cíngulo estende-se, em geral, sem qualquer deslocamento, mas também pode ser muito discreto, quase ausente. $\mathrm{O}$ sulco estende-se, conseqüentemente, sem qualquer torção tanto no epicone quanto no hipocone. Pode, inclusive, ir até o antiápice, isto é, até o ápice do hipocone. A película é muito fina e não apresenta qualquer estrutura. O citoplasma é hialino e apresenta cromoplastídios castanho-amarelados ou cianelas. Os cromoplastídios são parietais e podem ser discóides ou irregularmente fitáceos. Em algumas espécies, existe estigma na célula vegetativa, entretanto, este está sempre presente nos zoósporos. Rizopódios já foram observados nas células vegetativas.

Chave para as espécies e variedade de Amphidinium

1. Célula circular ou quase em seção transversal *A. ovoideum

1. Célula comprimida em seção transversal 
2. Hipocone em forma de domo ou subcônico

3. Sulco estendendo do cíngulo ao antiápice; epicone 0,5-0,6 da maior largura da célula

3. Sulco estendendo do subápice ao antiápice; epicone $0,7-0,8$ da maior largura da célula *A. lacustre *A. amphidinioides

2. Hipocone subesférico

4. Célula 10-14 $\mu$ m compr., 5-7 $\mu$ m larg.; cromoplastídios numerosos, granulares, esverdeados *A. kesslitzii var. kesslitzii

4. Célula ca. $26 \mu \mathrm{m}$ compr., ca. $18 \mu \mathrm{m}$ larg.; cromoplastídios numerosos, discóides, acastanhados *A. kesslitzii var. sanctipaulense

*A. amphidinioides (Geitler) Schiller, Dr. L. Rabenhorst's Kryptogamen-Flora von Deutschland, Österreich und der Schweiz 10(1): 278, fig. 265a-d. 1933 Eymnodinium amphidinioides Geitler, Botanisches Archiv 110: 110 , fig. a-f. $1924 \equiv A$. wigrense Wołoszyńska, Acta Societatis botanicorum Poloniae 3(1): 3, 8, fig. 1 . 1925.

Figuras 1-2

Célula aproximadamente ovóide, 1,3-1,8 vezes mais longa que larga, levemente achatada em seção transversal, 14-22 $\mu \mathrm{m}$ compr., 11-12 $\mu \mathrm{m}$ larg.; epicone reduzido, 0,7-0,8 da maior largura da célula, em forma de domo em vista frontal, hipocone semi-oblongo; cíngulo sem qualquer deslocamento; sulco estendendo do subápice até o antiápice; cromoplastídios numerosos, discóides, acastanhados.

Hábitat: planctônico.

A presença de A. amphidinioides (Geitler) Schiller no PEFI foi originalmente documentada por Bicudo \& Skvortzov (1970) como A. wigrense Wołoszyńska. Calado \& Moestrup (2005) consideraram A. wigrense Wołoszyńska idêntico a A. amphidinioides (Geitler) Schiller.

Amphidinium amphidinioides (Geitler) Schiller pode ser confundido, quanto à forma da célula, com A. lacustre Stein, do qual difere pelo sulco estender do subápice ao antiápice e pelo epicone relativamente mais largo.

O material em Bicudo \& Skvortzov (1970) foi coletado em 23 de dezembro de 1963 por B.V. Skvortzov de um lago natural no Parque Estadual das Fontes do Ipiranga. Contudo, não existe um lago natural no PEFI. Os ambientes com aparência lacustre são todos reservatórios e, portanto, artificiais. Apesar de se dispor de mais de 40 anos de coleta intensiva no PEFI, esta espécie jamais foi reencontrada.
*A. kesslitzii Schiller var. kesslitzii, Archiv für Protistenkunde 62(1): 135, fig. texto 11, pl. 5, fig. 12. 1928.

Figuras 3-4

Célula aproximadamente ovóide, ca. 2 vezes mais longa que larga, levemente achatada em seção transversal, 10-14 $\mu \mathrm{m}$ compr., 5-7 $\mu \mathrm{m}$ larg.; epicone e hipocone subesféricos em vista frontal; cintura sem qualquer deslocamento; sulco estendendo do cíngulo até $\mathrm{o}$ antiápice; cromoplastídios numerosos, granulares ou discóides, esverdeados.

Hábitat: planctônico.

A informação sobre os locais de coleta em Bicudo \& Skvortzov (1970) são muito vagas e dizem: lago natural e pequeno empoçado temporário no Parque Estadual das Fontes do Ipiranga. Ambos os locais foram visitados por B.V. Skvortzov, sendo o lago natural em 23 de dezembro de 1963 e o pequeno empoçado temporário em 20 de julho de 1965 e 28 de janeiro de 1967. Não existe, entretanto, lago natural no Parque; e os empoçados temporários surgem em quantidade, tamanho e localização variável no PEFI. Apesar de dispor de mais de 40 anos de coleta intensiva em vários ambientes do Parque, jamais foi re-encontrada esta espécie.

*A. kesslitzii Schiller var. sanctipaulense C. Bicudo \& Skvortzov, Rickia 5: 12, fig. 7. 1970. Figura 5

Célula aproximadamente ovóide, ca. 1,4 vezes mais longa que larga, levemente achatada em seção transversal, ca. $26 \mu \mathrm{m}$ compr., ca. $18 \mu \mathrm{m}$ larg.; epicone e hipocone subesféricos em vista frontal; cíngulo sem qualquer deslocamento; sulco estendendo do cíngulo até o antiápice; cromoplastídios numerosos, discóides, acastanhados.

Hábitat: planctônico.

Esta variedade difere da típica da espécie por apresentar a célula mais larga, aproximadamente o 
dobro do tamanho e por apresentar os cromoplastídios discóides, de coloração acastanhada.

Novamente, a informação sobre o local de coleta em Bicudo \& Skvortzov (1970) é muito vaga. Os autores o definem como um pequeno empoçado temporário no Parque Estadual das Fontes do Ipiranga. A coleta foi realizada por B.V. Skvortzov em 4 de julho de 1963. Apesar de dispor de mais de 40 anos de coleta intensiva em vários ambiente do PEFI, material desta variedade jamais foi re-encontrado.

*A. lacustre Stein, Der Organismus der Infusionstiere 3(2): 15, pl. 17, fig. 21-30. 1883.

Figura 6

Célula aproximadamente ovóide, ca. 1,5 vezes mais longa que larga, levemente achatada em seção transversal, 18-20 $\mu$ m compr., ca. $12 \mu \mathrm{m}$ larg.; epicone reduzido, 0,5-0,6 da maior largura da célula, hipocone em forma de domo até um tanto cordiforme em vista frontal; cíngulo sem qualquer deslocamento; sulco estendendo do cíngulo até o antiápice; cromoplastídios numerosos, discóides, castanho-amarelados.

Hábitat: planctônico.

Amphidinium lacustre Stein pode ser confundido, quanto à forma de sua célula, com Amphidinium turbo Kofoid \& Swezy. A diferença está em que esta última é uma espécie marinha, despigmentada, enquanto que A. lacustre Stein é habitante de águas continentais e é pigmentada.

O local de coleta em Bicudo \& Skvortzov (1970) está descrito de forma vaga, tornando difícil sua localização no Parque. Os referidos autores descreveram-no como um empoçado de chuva, visitado por B.V. Skvortzov em 30 de dezembro de 1966. Apesar de se dispor de mais de 40 anos de coleta intensiva no PEFI, esta espécie jamais foi re-encontrada.

O nome Amphidinium lacustre Stein foi considerado sinônimo de Prosoaulax lacustris (Stein) Calado \& Moestrup por Dodge (1982). Prosoaulax é um gênero exclusivamente marinho. Preferimos, por isso, a situação da espécie entre os Amphidinium, como fizeram, entre outros, Popovský \& Pfiester (1990).

*A. ovoideum (Lemmermann) Lemmermann, Hedwigia 39(4): 115. 1900 三 Prorocentrum ovoideum Lemmermann, Forschungsberichte Biologischen Station zu Plön 4: 147, fig. 1-3. 1896. Figuras 7-8
Célula mais ou menos globosa a ovóide, aproximadamente tão longa quanto larga ou ca. 1,5 vezes mais longa que larga, circular ou quase em seção transversal, 11-24 $\mu$ m compr., 11-14 $\mu$ m larg.; epicone em forma de domo em vista frontal, hipocone quase semicircular a subovóide, 2-4 vezes mais longo que o epicone; cíngulo sem qualquer deslocamento; sulco presentemente não observado; cromoplastídios numerosos, granulares, esverdeados.

Hábitat: planctônico.

Parke \& Dixon (1976) citaram as autoridades desta espécie como Amphidinium ovoideum (Lemmermann) Kofoid \& Swezy.

Amphidinium ovoideum (Lemmermann) Lemmermann pode ser comparado, quanto à forma da célula, com Amphidinium operculatum Claparède \& Lachmann, porém, difere no tamanho dos seus representantes e na forma e no tamanho dos cromoplastídios.

Conforme Popovský \& Pfiester (1990), esta espécie ocorre em águas salobras na Alemanha e doces na América do Sul.

Ainda uma vez, deve-se mencionar que o local de coleta foi descrito de forma vaga em Bicudo \& Skvortzov (1970), tornando difícil sua situação no Parque Estadual das Fontes do Ipiranga. Bicudo \& Skvortzov (1970) descreveram a localidade como um lago natural, mas não existem ambientes lênticos no PEFI. O local foi visitado por B.V. Skvortzov em 4 de janeiro de 1965. Apesar de havermos coletado intensivamente na área do PEFI há mais de 40 anos, A. ovoideum (Lemmermann) Lemmermann jamais foi re-encontrado.

\section{Gymnodinium Stein}

Indivíduos unicelulares, de hábito solitário, que nadam ativamente. Raramente formam cadeias e quando formam, estas têm duração efêmera e são constituídas por poucos indivíduos. A forma da célula varia de esférica a mais ou menos ovóide ou, mais raramente, pode ser um tanto quadrática em vista ventral (taxonômica). A seção transversal da célula pode, algumas vezes, ser um pouco achatada dorsiventralmente, com projeções de pequeno porte. O cíngulo apresenta-se na forma de uma espiral descendente para a esquerda, que circunda inteiramente a célula e se desloca menos do que $1 / 5$ do comprimento total da célula. O sulco pode estender-se do ápice ao antiápice da célula. A célula é nua, mas também pode apresentar uma película 
bastante delicada, cuja superfície é lisa ou estriada. Os cromoplastídios são discóides, pequenos, variam em número de um ou dois até muitos e podem ser parietais ou irradiar de um centro comum na célula. Há indivíduos que possuem cianelas em vez de cromoplastídios e outros, embora poucos, que são totalmente destituídos de cromoplastídios e cianelas. Algumas espécies apresentam ejectissomos. Estigma, quando presente, ocorre em zoósporos e gametas.

Chave para as espécies de Gymnodinium

1. Célula com epicone em forma de domo e hipocone cônico G. fuscum

1. Célula com epicone e hipocone semisféricos ou quase

2. Célula com sulco distinto pelo menos no hipocone *G. biciliatum

2. Célula sem sulco distinto......* G. simplex *G.iciliatum Ohno, Journal of the College of Science, Imperial University of Tokyo 32: 77-91, pl.

Figura 9 1, fig. 1-37. 1911.

Indivíduo unicelular, solitário, livre-natante; célula amplamente elipsóide, ca. 1,5 vezes mais longa que larga, circular ou quase em seção transversal, 9-11 $\mu \mathrm{m}$ compr., 6-7 $\mu \mathrm{m}$ larg.; cíngulo transversal pré-mediano; sulco curto, apenas no epicone, estendendo até próximo do antiápice; cromoplastídios elipsóides, acastanhados, aglomerados na porção central da célula. Hábitat: planctônico.

Gymnodinium biciliatum Ohno pode ser morfologicamente confundido com G. bogoriense Klebs e G. ordinatum Skuja, dos quais difere apenas pela seção transversal circular ou quase de sua célula.

A descrição original de G. biciliatum Ohno menciona a existência de três flagelos por célula, dois dos quais são longitudinais. Segundo Kofoid \& Swezy (1921), o espécime ilustrado em Ohno (1911) deve, muito provavelmente, estar em processo de divisão celular (mitose), pois os flagelos são, de modo geral, as primeiras estruturas celulares a exibirem sinais de divisão e, não raramente, resulta no aparecimento precoce do novo flagelo sem que a célula apresente qualquer outro sinal de mitose.

A espécie foi coletada uma única vez, por B.V. Skvortzov, dia 1 de fevereiro de 1966, de uma lagoa artificial no Parque Estadual das Fontes do Ipiranga.
G. fuscum (Ehrenberg) Stein, Der Organismus der Infusionstiere 3(2): 95, 97. $1883 \equiv$ Peridinium fuscum Ehrenberg, Abhandlungen der preussischen Akademie der Wissenschaften 1833: 270. 1834.

Figuras 10-11

Indivíduo unicelular, solitário, livre-natante; célula subovóide, 1,6-2 vezes mais longa que larga, comprimida em seção transversal, (40-)70-92 $\mu \mathrm{m}$ compr., (25-)37-42 $\mu \mathrm{m}$ larg.; epicone em forma de domo, hipocone cônico, ambos aproximadamente do mesmo comprimento; cíngulo equatorial, completo ou em espiral suave; sulco estendendo muito pouco no epicone, até mais ou menos a metade do hipocone; cromoplastídios elipsóides, castanhos a castanho-amarelados, irradiando da porção central da célula.

Hábitat: planctônico.

Gymnodinium fuscum (Ehrenberg) Stein lembra, morfologicamente, G. caudatum Prescott, mas é diferente no tamanho de seus representantes, pois os da última espécie atingem tamanhos maiores, da ordem de 104-118 × 65-70 $\mu \mathrm{m}$. Gymnodinium caudatum Prescott também possui um processo caudal (caudus) bem distinto. Thompson (1947) observou que certos espécimes de G. fuscum (Ehrenberg) Stein formam um processo caudal imediatamente antes de entrarem em divisão celular, o que sugere a possibilidade de G. fuscum (Ehrenberg) Stein e G. caudatum Prescott constituírem uma única espécie, onde os representantes da última nada mais seriam do que exemplares maiores da primeira espécie.

A espécie foi bastante comum no Lago das Ninféias e no hidrofitotério do Jardim Botânico de São Paulo ocorrendo, principalmente, durante o fim da primavera (fim de outubro e em novembro) e início do outono (meado de abril e em maio). O material identificado em Bicudo \& Skvortzov (1970) e coletado em três ocasiões ( 03 de maio de 1965, 13 de maio de 1965 e 29 de junho de 1963) pelo último autor, proveio de uma 'lagoa artificial' que, muito provavelmente, seja o Lago das Ninféias.

*G. simplex (Lohmann) Kofoid \& Swezy, Memoirs of the University of California 5: 256, fig. BB, 8. $1921 \equiv$ Protodinium simplex Lohmann, Wissenschaftliche Meeresuntersuchungen der Kommission zur wissenschaftlichen Untersuchung der deutschen Meere 10: 264, pl. 17, fig. 17. 1908. Figura 12 
Indivíduo unicelular, solitário, livre-natante; célula amplamente elipsóide, ca. 1,5 vezes mais longa que larga, circular em seção transversal, 35-45 $\mu \mathrm{m}$ compr., 23-31 um larg.; cíngulo formando um círculo fechado; sulco longitudinal ausente; cromoplastídios elipsóides, amarelados.

Hábitat: planctônico.

O material examinado proveio de um pequeno empoçado temporário situado no Parque Estadual das Fontes do Ipiranga. A descrição da proveniência da amostra é demasiadamente vaga, tornando impossível retornar ao local para uma nova coleta. O local foi visitado por B.V. Skvortzov em 28 de janeiro de 1967. Apesar de haver coletado intensivamente em toda a área do PEFI por mais de 40 anos, G. simplex (Lohmann) Kofoid \& Swezy jamais foi reencontrado.

\section{Katodium Fott}

Indivíduos unicelulares, livre-natantes e de hábito solitário. A forma da célula varia desde esférica até elipsóide, ovóide ou semelhante a um cogumelo. São, de modo geral, dorsiventralmente achatados. $\mathrm{O}$ cíngulo situa-se posteriormente na célula e pode ser torcido em hélice, mas sempre resultando em um epicone mais ou menos duas vezes mais comprido e mais largo que o hipocone. O sulco é geralmente obscuro, mas, às vezes, pode se estender até o hipocone. A parede celular é muito fina e não apresenta estruturação. Em K. mazuricum Javornický a parede parece ser constituída por plaquetas muito delicadas, estriadas, distribuídas por todo o corpo e, exteriormente, por escamas triangulares. Os cromoplastídios são numerosos, discóides, castanho-amarelados e ocupam posição parietal na célula. Em K. mazuricum Javornický existe apenas um cromoplastídio grande por célula, que preenche quase todo o protoplasma e tem forma laminar e bordo irregularmente lobado. Algumas espécies como, por exemplo, K. woloszynskae (Schiller) Loeblich III e K. stigmaticum (Lindemann) Loeblich III não possuem cromoplastídos. Katodinium montanum (Schiller) Loeblich III possui cianelas em vez de cromoplastídios. Katodinium edax (Schiller) Loeblich III, K. montanum (Schiller) Loeblich III e K. stigmaticum (Lindemann) Loeblich III possuem estigma na célula vegetativa.

O nome Katodinium foi proposto por Fott (1957) para substituir Massartia Conrad 1926, pois este é um homônimo posterior de Massartia De Wildemann 1897, um ficomiceto.
Chave para as espécies de Katodinium

1. Célula subcilíndrica em vista frontal; seção transversal circular ou quase *K. sanctipaulense

1. Célula ovóide em vista frontal; seção transversal amplamente elíptica. *K. fontinalis

*K. fontinalis C. Bicudo \& Skvortzov, Rickia 5: 15, fig. 14-15. 1970.

Figuras 13-14

Indivíduo unicelular, solitário, livre-natante; célula aproximadamente ovóide, assimétrica, elíptica em seção transversal, 1,3-1,4 vezes mais longa que larga, 8-9 $\mu$ m compr., ca. $4 \mu \mathrm{m}$ larg.; epicone semi-elíptico, ca. 2 vezes mais longo que o hipocone, hipocone semigloboso; cíngulo posterior, formando um círculo contínuo ou uma hélice suave; sulco não observado; cromoplastídios numerosos, discóides, castanhoamarelados, situados no epicone.

Hábitat: planctônico.

O presente material foi coletado por B.V. Skvortzov em 6 de dezembro de 1966, de um pequeno corpo d'água temporário situado no Parque Estadual das Fontes do Ipiranga. Ocorreu entre filamentos de Tribonema sp.

Bicudo \& Skvortzov (1970) consideram K. fontinalis C. Bicudo \& Skvortzov uma espécie facilmente identificada pela forma aproximadamente ovóide e assimétrica, bem como pelo diminuto tamanho de seus indivíduos representantes.

*K. sanctipaulense C. Bicudo \& Skvortzov, Rickia 5: 14, fig. 13. 1970.

Figura 15

Indivíduo unicelular, solitário, livre-natante; célula aproximadamente elipsóide a subcilíndrica, assimétrica, circular ou quase em seção transversal, ca. 2 vezes mais longa que larga, 13-16 $\mu \mathrm{m}$ compr., 6-8 $\mu \mathrm{m}$ larg.; epicone semi-elíptico, ca. 3 vezes mais longo que o hipocone, hipocone subhemisférico; cíngulo posterior em hélice suave; sulco não observado; cromoplastídios numerosos, discóides, amarelados a castanho-amarelados, situados somente no epicone. Hábitat: planctônico.

O material examinado foi coletado por B.V. Skvortzov em 17 de fevereiro de 1967, de um corpo d'água permanente localizado do Parque Estadual das Fontes do Ipiranga. Ocorreu entre filamentos de 
Spirogyra sp.

Conforme Bicudo \& Skvortzov (1970), trata de uma espécie marcante pela forma aproximadamente elipsóide a subcilíndrica, assimétrica, circular ou quase em seção transversal dos indivíduos. Pode, entretanto, ser comparada com $K$. ruppiae (Conrad) Loeblich, da qual é distinta por apresentar pigmentação e o hipocone mais desenvolvido.

\section{HEMIDINIACEAE}

Estão incluídos nesta família os indivíduos unicelulares ativamente móveis na fase vegetativa, de vida livre e hábito isolado, cujo periplasto é envolvido por uma teca muito delicada. Epiteca e hipoteca possuem tamanhos freqüentemente diferentes entre si. As plaquetas são difíceis de ser observadas ao microscópio óptico e estão distribuídas da seguinte forma: 6', 0a, 6"; 5", lp, 1"'". O cíngulo é incompleto, envolvendo a metade ou até $2 / 3$ da circunferência da célula. $\mathrm{O}$ cíngulo é normal e estende-se na hipoteca sem, entretanto, alcançar a epiteca. Os cromoplas- tídios estão usualmente presentes e são numerosos por indivíduo.

\section{Hemidinium Stein}

Indivíduos ativamente livre-natantes, de vida isolada, cuja forma da célula varia entre elipsóide a mais ou menos ovóide em vista ventral (taxonômica), porém, sempre dorsiventralmente achatada. Os pólos são arredondados, sendo o posterior mais amplamente arredondado que o anterior, que também pode ser cônico. O cíngulo é incompleto, curvado para a hipoteca. O sulco longitudinal é estreito e estende até o pólo posterior. A parede celular é bastante fina e revestida por uma teca bastante delicada, constituída por plaquetas lisas, areoladas, de difícil visualização ao microscópio óptico. Os cromoplastídios são numerosos, elíptico-alongados, distribuem-se radialmente a partir do centro da célula e possuem coloração castanho-amarelada a castanha. Algumas espécies mostram estigma na fase vegetativa de seu histórico de vida.

Chave para as espécies e variedade de Hemidinium

1. Célula com hipoteca e epiteca de tamanhos aproximadamente iguais ou epiteca menor que a hipoteca

2. Célula 11-14 $\mu$ m compr., 8-11 $\mu$ m larg.; 1-4 cromoplastídios por célula *H. pseudochraceum

2. Célula 28-45 $\mu \mathrm{m}$ compr., 18-27 $\mu \mathrm{m}$ larg., numerosos cromoplastídios por célula

*H. nasutum var. tatricum

1. Célula com hipoteca menor que a epiteca

3. Cromoplastídio único por célula, laminar

*H. montanum

3. Cromoplastídios numerosos, discóides

*H. brasiliense

*H. brasiliense C. Bicudo \& Skvortzov, Rickia 5: 16, fig. 16, 19-20. 1970.

Figuras 16-18

Indivíduo unicelular, solitário, livre-natante; célula aproximadamente elíptica, simétrica, elíptica em seção transversal, 1,5-1,7 vezes mais longa que larga, 18-30 $\mu \mathrm{m}$ compr., 12-18 $\mu \mathrm{m}$ larg.; epiteca hemisférica alongada, 1/3-1/2 do comprimento total da célula, hipoteca subhemisférica; cíngulo formando um semicírculo, situado mais ou menos horizontalmente; sulco longitudinal não observado; cromoplastídios numerosos, castanho-amarelados, discóides, irregularmente dispersos ou em forma de bastonetes, radialmente arranjados.

Hábitat: planctônico.

O presente material do PEFI foi coletado por B.V. Skvortzov em quatro ocasiões. A primeira foi de uma lagoa artificial no dia 29 de junho de 1963; a segunda de um empoçado temporário de água de chuva no dia 30 de dezembro de 1966; a terceira de um ambiente temporário no dia 28 de janeiro de 1967; e a quarta também de um empoçado temporário no dia 14 de fevereiro de 1967. Todos os três ou quatro locais estão situados no Parque Estadual das Fontes do Ipiranga. Entretanto, a identificação desses locais é demasiadamente vaga em Bicudo \& Skvortzov (1970), para que se possa retornar a eles e providenciar novas coletas. Assim sendo, o conhecimento de H. brasiliense C. Bicudo \& Skvortzov está hoje inteiramente baseado em sua publicação original.

Hemidinium brasiliense C. Bicudo \& Skvortzov lembra, morfologicamente, H. nasutum Stein, do qual é distinto por possuir células mais simétricas e diferente relação entre o comprimento da epiteca e da hipoteca. 
*H. montanum C. Bicudo \& Skvortzov, Rickia 5: 17, fig. 17-18. 1970.

Figuras 19-20

Indivíduo unicelular, solitário, livre-natante; célula globosa a elíptica, assimétrica, fortemente achatada em seção transversal, 1,4-2 vezes mais longa que larga, 11-26 $\mu \mathrm{m}$ compr., 8-16,5 $\mu \mathrm{m}$ larg.; epiteca hemisférica alongada, ca. 1/3 do comprimento total da célula, hipoteca subhemisférica; cíngulo formando um semicírculo levógiro, descendente, suave; sulco longitudinal não observado; cromoplastídio 1, verdeamarelado, laminar, situado na epiteca.

Hábitat: planctônico.

O presente material foi coletado por B.V. Skvortzov em quatro ocasiões, como aconteceu com a espécie anterior. A primeira ocasião foi em 16 de maio de 1965; a segunda em 16 de julho de 1965; a terceira em 18 de maio de 1966; e a quarta ocasião em 23 de fevereiro de 1967. Em todas as ocasiões, o material foi coletado de um pequeno empoçado temporário. A falta de maiores detalhes na descrição dos locais de coleta não permite, entretanto, saber se o aludido pequeno empoçado temporário é o mesmo em todas as ocasiões.

Segundo Bicudo \& Skvortzov (1970), H. montanum C. Bicudo \& Skvortzov pode ser confundido com $H$. ochraceum Levander, mas difere, fundamentalmente, pela posse de um único cromoplastídio laminar por célula e, em segundo plano, pelo comprimento relativo da epiteca e da hipoteca.

*H. nasutum Stein var. tatricum Wołoszyńska, Acta Societatis botanicorum Poloniae 7: 500, 504, pl. 27, fig. 1-8. 1930.

Figura 21

Indivíduo unicelular, solitário, livre-natante; célula elipsóide alongada, assimétrica, acentuadamente elíptica em seção transversal, 1,5-1,7 vezes mais longa que larga, 28-45 $\mu \mathrm{m}$ compr., 18-27 $\mu \mathrm{m}$ larg.; epiteca subhemisférica, ca. 1/2 do comprimento total da célula, hipoteca subhemisférica, pouco mais comprimida que a epiteca; cíngulo formando um semicírculo em espiral suave apenas na epiteca; sulco longitudinal atingindo o antiápice; cromoplastídios numerosos, castanhos, elípticos, radiando do centro da célula.

Hábitat: planctônico.

Hemidinium nasutum Stein var. tatricum Wołoszyńska foi coletado apenas duas vezes no hidrofitotério do Jardim Botânico de São Paulo. A primeira vez foi em 1966, fazendo parte de comunidades flutuantes que surgiram no hidrofitotério, cuja composição taxonômica foi estudada por Bicudo \& Bicudo (1967). Este material não foi preservado nem dele há ilustração. Posteriormente, C.E.M. Bicudo coletou material do mesmo hidrofitotério. O material estudado não foi preservado, mas há ilustração feita com câmara-clara.

Hemidinium nasutum Stein var. tatricum Wołoszyńska difere da variedade-tipo da espécie pelo maior achatamento dorsiventral da célula e por possuir só uma grande plaqueta do lado direito do cíngulo. Alguns autores consideram a var. tatricum Wołoszyńska sinônimo da típica da espécie, com o que não concordamos por conta do número de plaquetas do lado direito do cíngulo: a variedade típica tem duas e a var. tatricum Wołoszyńska apenas uma. A observação das plaquetas nesta espécie (incluindo a var. tatricum Wołoszyńska) é, entretanto, impossível com o conteúdo protoplasmático e bastante difícil quando livre do protoplasma.

*H. pseudochraceum C. Bicudo \& Skvortzov, Rickia 5: 17, fig. 21-22. 1970.

Figuras 22-23

Indivíduo unicelular, solitário, livre-natante; célula subesférica a ovóide, assimétrica, suavemente elíptica em seção transversal, 1,3-1,4 vezes mais longa que larga, 11-14 $\mu \mathrm{m}$ compr., 8-11 $\mu \mathrm{m}$ larg.; epiteca subhemisférica, ca. 1/2 do comprimento total da célula, hipoteca subhemisférica, pouco mais comprimida que a epiteca; cíngulo formando espiral levógira, descendente, suave, apenas na epiteca; sulco longitudinal não observado; cromoplastídios poucos (1-4), amarelo-esverdeados, discóides, irregularmente dispersos.

Hábitat: planctônico.

O presente material foi coletado por B.V. Skvortzov em uma única ocasião, 23 de fevereiro de 1967, de um pequeno corpo d'água temporário situado no Parque Estadual das Fontes do Ipiranga.

Hemidium pseudochraceum C. Bicudo \& Skvortzov lembra $H$. ochraceum Levander, do qual difere pelo tamanho menor de sua célula e pelo menor número de cromoplastídios (Bicudo \& Skvortzov 1970).

\section{DINOCOCCACEAE}

Algas unicelulares cocóides, que ocorrem no plâncton ou presas a algum substrato. A reprodução assexuada é feita por meio de estruturas amebóides, 
esporócitos, autósporos ou zoósporos; e a sexuada por gametas cuja morfologia inclui cíngulo, sulco e dois tipos distintos de flagelos lembra a das formas vegetativas flageladas. O dinocário não é visível no estádio amebóide. A maioria das formas classificadas nesta família é pigmentada, mas também ocorrem outras não-pigmentadas. As primeiras são dominantemente autótrofas, mas também podem ser simultaneamente heterótrofas, porém, em menor escala. As formas despigmentadas são holofíticas, ou seja, fagocitam através de haustórios de comprimentos variáveis.

\section{Dinococcus Fott}

Os indivíduos de Dinococcus são sempre fixos a algum tipo de substrato através de um disco ou de um estipe bastante visível na fase vegetativa. A forma da célula é triangular em vista frontal (taxonômica). Em vista lateral, pode ser faseoliforme ou lunada e em vista apical, elipsóide ou ovóide. Os pólos terminam em um espinho bastante grosseiro, entretanto, relativamente curto. A margem superior da célula pode ser reta ou apresentar uma depressão mediana mais ou menos acentuada. As margens basais podem ser retas ou suavemente convexas. A parede celular é muito fina e não apresenta qualquer estrutura. Os cromoplastídios são numerosos e podem ser elípticos, um tanto clavados ou estrelados e distribuem-se parietalmente, de maneira radial, a partir da porção central da célula. Pode ocorrer pirenóide e estigma em alguns representantes deste gênero.

O nome Raciborskia Wołoszyńska 1919 é supérfluo devido à existência de homônimo anterior, Raciborskia A.N. Berlese \& P.A. Saccardo 1888, um fungo. Fott (1960) propôs o nome substituto Dinococcus para a alga. Conforme originalmente salientado por Bicudo \& Menezes (2006), a autoridade do gênero é, portanto, Dinococcus Fott e não Dinococcus (Wołoszyńska) Fott, como é usualmente referido na literatura.

Apenas uma espécie identificada.

D. bicornis (Wołoszyńska) Fott, Preslia 32(2): 150. $1960 \equiv$ Raciborskia bicornis Wołoszyńska, Bulletin de la Académie des Sciences Cracovie: sér. B, 58: 199, pl. 14, fig. 15-17. 1919.

Figura 24

Indivíduo unicelular, solitário ou gregário, fixo ao substrato por 1 estipe curto, 23-30 $\mu \mathrm{m}$ compr., 11,5-16 $\mu \mathrm{m}$ larg.; célula triangular em vista frontal, elíptica em vista apical, pólos terminados em 1 espinho grosseiro, curto; margem superior uniformemente convexa ou 1 depressão mediana mais ou menos acentuada; margens basais suavemente convexas; cromoplastídios numerosos, castanhos, discóides, com pirenóide.

Hábitat: planctônico.

O presente material foi coletado várias vezes, sempre no hidrofitotério, sobre filamentos de algas, principalmente de Oedogonium spp.

Dinococcus bicornis (Wołoszyńska) Fott é facilmente reconhecido por possuir pirenóide e os cromoplastídios não arranjados radialmente. Conforme Popovský \& Pfiester (1990), entretanto, provavelmente só exista uma espécie de Dinococcus, que seria dotada de grande variação morfológica, ecológica e nutricional. Sucede, a nosso ver, que a maioria dos trabalhos florísticos em algas de águas continentais focaliza apenas o material planctônico. Maior estudo de material do perifíton, que inclua observação taxonômica e ecológica, será imprescindível para resolver esta pendência.

As coletas na área do PEFI já duram mais do que 40 anos, contudo, quase nenhum material de Dinophyceae não-tecadas (nuas) ou com teca constituída por plaquetas de difícil visualização foi coletado. Por conseguinte, todo o conhecimento dos materiais ora descritos, exceto os de Gymnodinium fuscum (Ehrenberg) Stein, Hemidinium nasutum Stein var. tatricum Wołoszyńska e Dinococcus bicornis (Wołoszyńska) Fott, provém de suas descrições originais, que constituem os únicos documentos disponíveis sobre as demais espécies ora estudadas. Tais descrições são, contudo, suficientemente completas e as ilustrações contêm as características diagnósticas que permitem sua pronta identificação. De todos os materiais identificados, somente a descrição de Amphidinium kesslitzii Schiller var. sanctipaulense C. Bicudo \& Skvortzov foi baseada em um único espécime. Mas, esse espécime é suficientemente distinto de tudo que foi descrito até então, de modo que o nome da variedade deve prevalecer até que mais material seja coletado e estudos mais aprofundados realizados, permitindo seu conhecimento mais detalhado e adequado.

As Dinophyceae não-tecadas e aquelas com plaquetas de difícil visualização são organismos dominantemente planctônicos. Embora os especialistas em algas de águas continentais coletem predominantemente plâncton, é difícil explicar porque em suas 

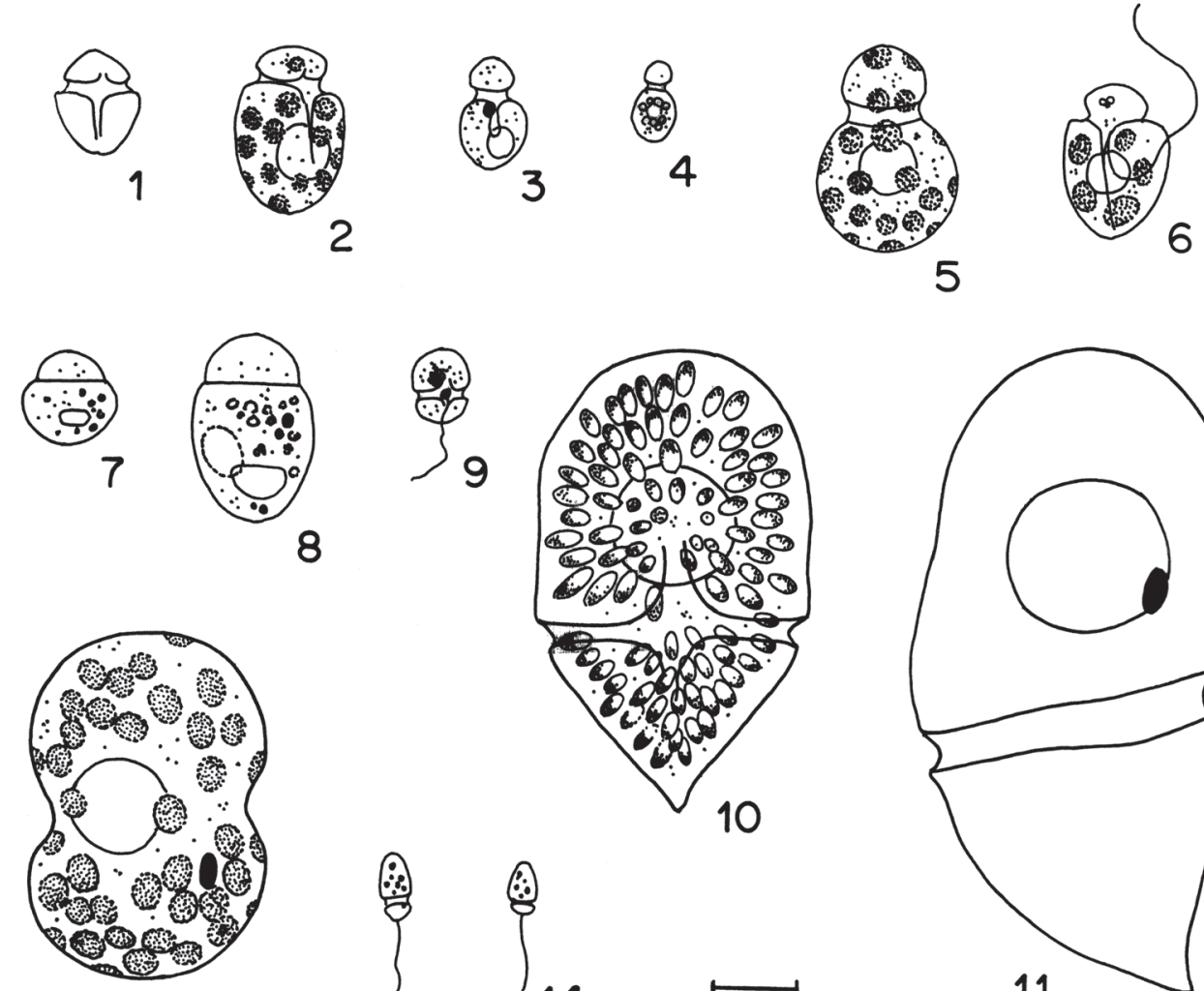

12
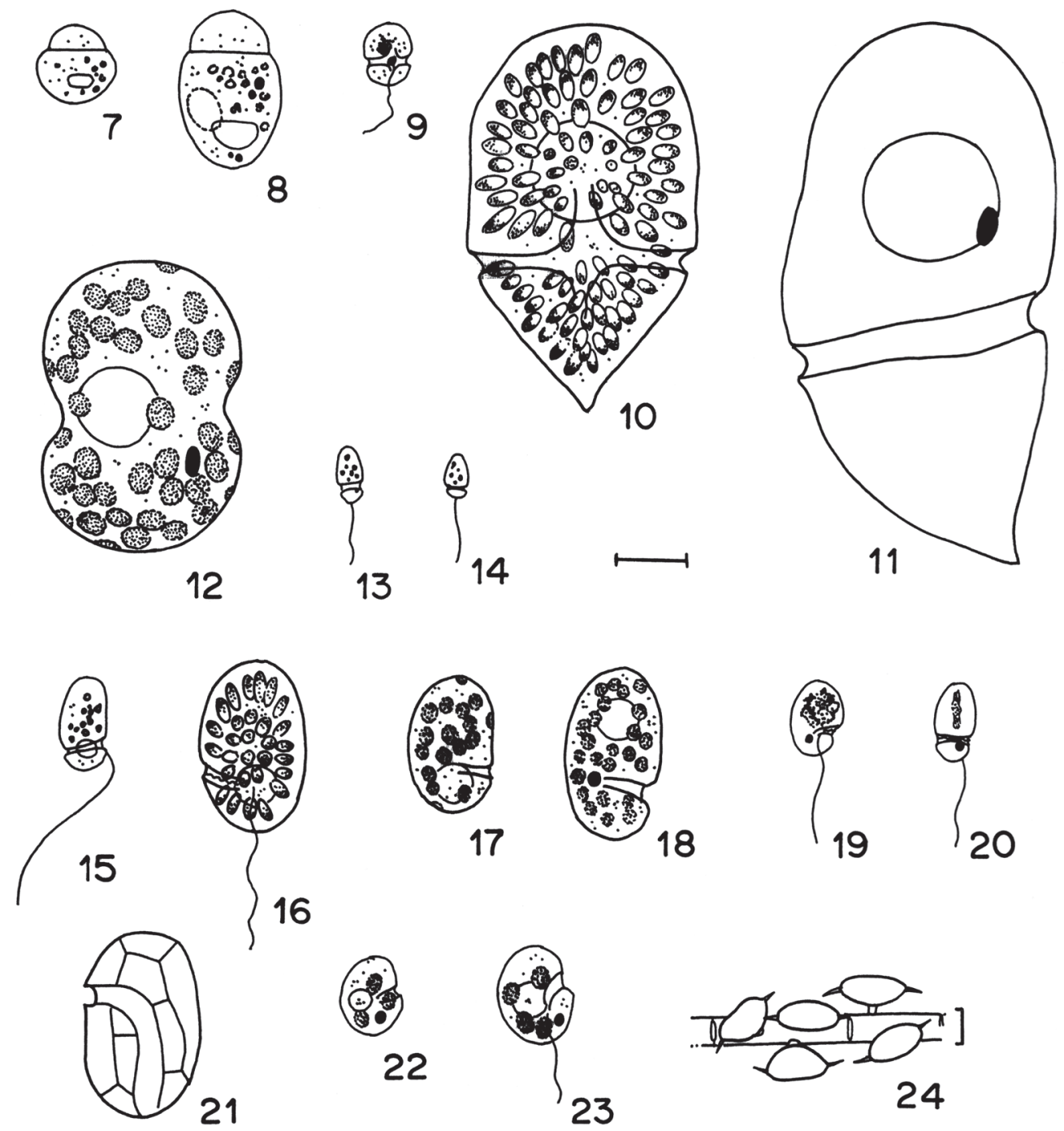

Figuras 1-24. Espécies de Dinococcaceae, Gymnodiniaceae e Hemidiniaceae do Parque Estadual das Fontes do Ipiranga. 1-2. Amphidinium amphidinioides (Bicudo \& Skvortzov 1970). 3-4. A. kesslitzii var. kesslitzii (Bicudo \& Skvortzov 1970). 3. Vista ventral. 5. A. kesslitzii var. sanctipaulense (Bicudo \& Skvortzov 1970). 6. A. lacustre (Bicudo \& Skvortzov 1970). 7-8. A. ovoideum (Bicudo \& Skvortzov 1970). 9. Gymnodinium biciliatum (Bicudo \& Skvortzov 1970). 10-11. G. fuscum. 10. Vista ventral. 12. G. simplex (Bicudo \& Skvortzov 1970). 13-14. Katodinium fontinalis (Bicudo \& Skvortzov 1970). 15. K. sanctipaulense (Bicudo \& Skvortzov 1970). 16-18. Hemidinium brasiliense (Bicudo \& Skvortzov 1970). 19-20. H. montanum (Bicudo \& Skvortzov 1970). 21. H. nasutum var. tatricum. $22-23$. H. pseudochraceum (Bicudo \& Skvortzov 1970). 24. Dinococcus bicornis. Escala $=10 \mu \mathrm{m}$.

Figures 1-24. Species of Dinococcaceae, Gymnodiniaceae and Hemidiniaceae from the "Parque Estadual das Fontes do Ipiranga". 1-2. Amphidinium amphidinioides (Bicudo \& Skvortzov 1970). 3-4. A. kesslitzii var. kesslitzii (Bicudo \& Skvortzov 1970). 3. Ventral view. 5. A. kesslitzii var. sanctipaulense (Bicudo \& Skvortzov 1970). 6. A. lacustre (Bicudo \& Skvortzov 1970). 7-8. A. ovoideum (Bicudo \& Skvortzov 1970). 9. Gymnodinium biciliatum (Bicudo \& Skvortzov 1970). 10-11. G. fuscum. 10. Ventral view. 12. G. simplex (Bicudo \& Skvortzov 1970). 13-14. Katodinium fontinalis (Bicudo \& Skvortzov 1970). 15. K. sanctipaulense (Bicudo \& Skvortzov 1970). 16-18. Hemidinium brasiliense (Bicudo \& Skvortzov 1970). 19-20. H. montanum (Bicudo \& Skvortzov 1970). 21. H. nasutum var. tatricum. 22-23. H. pseudochraceum (Bicudo \& Skvortzov 1970). 24. Dinococcus bicornis. Scale bar $=10 \mu \mathrm{m}$. 
coleções as formas dinoflageladas acima estejam tão pouco representadas. Talvez, o fato de serem organismos muito delicados, os torne de difícil fixação e preservação. Os diversos estudos ecológicos que versaram sobre a composição e a dinâmica da comunidade fitoplanctônica realizados no PEFI jamais mostraram representantes deste grupo de flagelados, exceto de G. fuscum (Ehrenberg) Stein. Não se pode, pois, por um lado, conjeturar sobre a sazonalidade de tais organismos, que poderia explicar sua aparente raridade no PEFI. Por outro lado, entretanto, as coletas feitas por B.V. Skvortzov foram realizadas em tempos de seca e de chuva, o que pode mostrar que esses organismos estão presentes nas águas do PEFI, se não durante o ano todo, pelo menos em boa parte dele.

As descrições dos ambientes coletados por B.V. Skvortzov são vagas, tão vagas que sua localização se torna, na prática, impossível. As indicações de procedência desses locais referem-nos como sendo um lago natural, um lago artificial ou um pequeno empoçado temporário. Sabe-se, entretanto, que não existe nenhum ambiente lacustre (lêntico) natural no PEFI. Todos os ambientes com aparência de lacustre são, de fato, reservatórios, ou seja, ambientes semilênticos barrados artificialmente para abastecimento público (Reservatório das Garças), ou para fins de composição paisagística (Reservatório das Ninféias) ou de exibição de plantas aquáticas (hidrofitotério) no Jardim Botânico de São Paulo. Além disso, a falta de maiores detalhes não permite saber se o que B.V. Skvortzov refere em seus trabalhos como "pequeno empoçado temporário" é o mesmo em todas as ocasiões ou se são ambientes distintos. O fato é que durante pouco mais de 40 anos de coletas em vários ambientes do PEFI jamais foram encontrados representantes de dinoflagelados nus ou com teca formada por plaquetas de difícil visualização, exceto de Gymnodinium fuscum (Ehrenberg) Stein (Lago das Ninféias e hidrofitotério) e Dinococcus bicornis (Wołoszyńska) Fott (hidrofitotério).

O material estudado por Bicudo \& Skvortzov (1970) não foi depositado no Herbário Científico do Estado "Maria Eneyda P. Kauffmann Fidalgo" (SP), por se tratar de organismos extremamente delicados, de difícil fixação e preservação. Os materiais-tipo das espécies lá propostas são suas ilustrações originais.

Material excluído - Bicudo \& Bicudo (1967) registraram a presença de Amphidinium sp. nas comunidades flutuantes que ocorreram no hidrofitotério do Jardim Botânico de São Paulo. O material estudado não foi preservado nem dele há descrição e/ou ilustração que permitisse sua reidentificação. Na impossibilidade de saber exatamente o que é Amphidinium sp. optamos, presentemente, por excluí-lo do presente trabalho.

Chave geral

1. Célula fixa a algum substrato

(Dinococcus) D. bicornis

1. Célula móvel, não fixa a algum substrato

2. Cíngulo localizado aproximadamente no meio da célula; epicone e hipocone de tamanhos iguais ou quase (Gymnodinium)

3. Célula com epicone em forma de domo e hipocone cônico G. fuscum

3. Célula com epicone e hipocone semisféricos ou quase

4. Célula com cíngulo distinto pelo menos no hipocone *G. biciliatum

4. Célula sem cíngulo distinto *G. simplex

2. Cíngulo localizado anterior ou posteriormente na célula; epicone e hipocone de tamanhos desiguais

5. Cíngulo envolvendo parcialmente a célula (Hemidinium)

6. Célula com hipoteca e epiteca de tamanhos aproximadamente iguais

7. Célula 11-14 $\mu$ m compr., 8-11 $\mu$ m larg.; 1-4 cromoplastídios por célula .... * H. pseudochraceum

7. Célula 28-45 um compr., 18-27 $\mu \mathrm{m}$ larg., numerosos cromoplastídios por célula

H. nasutum var. tatricum

6. Célula com hipoteca menor que a epiteca

8. Cromoplastídio único por célula, laminar

*H. montanum

8. Cromoplastídios numerosos, discóides

$* H$. brasiliense

5. Cíngulo envolvendo completamente a célula 
9. Cíngulo localizado anteriormente na célula; epicone menor que o hipocone

10. Célula circular ou quase em seção transversal (Amphidinium)

10. Célula achatada em seção transversal

11. Hipocone em forma de domo ou subcônico

12. Sulco longitudinal estendendo do cíngulo ao antiápice; epicone $0,5-0,6$ da maior largura da célula *A. lacustre

12. Sulco longitudinal estendendo do subápice ao antiápice; epicone $0,7-0,8$ da maior largura da célula *A. amphidinioides

11. Hipocone subesférico

13. Célula 10-14 $\mu$ m compr., 5-7 $\mu \mathrm{m}$ larg.; cromoplastídios numerosos, granulares, esverdeados *A. kesslitzii var. kesslitzii

13. Célula ca. $26 \mu \mathrm{m}$ compr., ca. $18 \mu \mathrm{m}$ larg.; cromoplastídios numerosos, discóides, acastanhados *A. kesslitzii var. sanctipaulense

9. Cíngulo localizado posteriormente na célula; epicone maior que o hipocone (Katodinium)

14. Célula subcilíndrica em vista frontal; seção transversal circular ou quase *K. sanctipaulense

14. Célula ovóide em vista frontal; seção transversal amplamente elíptica * K. fontinalis

\section{Agradecimentos}

O autor é imensamente grato ao CNPq, Conselho Nacional de Desenvolvimento Científico e Tecnológico pelo financiamento parcial desta pesquisa (Processo $\left.n^{\circ} 303876 / 2004-2\right)$.

\section{Literatura citada}

Bicudo, C.E.M. \& Bicudo, R.M.T. 1967. Floating communities of algae in an artificial pond in the Parque do Estado, São Paulo, Brazil. Journal of Phycology 3: 233-234.

Bicudo, C.E.M. \& Menezes, M. 2006. Gêneros de algas de águas continentais do Brasil: chave para identificação e descrições. 2 ed. RiMa Editora, São Carlos.

Bicudo, C.E.M. \& Skvortzov, B.V. 1970. Contribution to the knowledge of Brazilian Dinophyceae: free-living unarmored genera. Rickia 5: 5-21.

Calado, A.J. \& Moestrup, Ø. 2005. On the freshwater dinoflagellates presently included in the genus Amphidinium, with a description of Prosoaulax gen. nov. Phycologia 44: 112-119.
Dodge, J.D. 1982. Marine Dinoflagellates of the British Isles. Her Majesty's Stationery Office, London.

Fott, B. 1957. Taxonomie drobnohledné flory naisch vod. Preslia 29: 278-319.

Fott, B. 1960. Taxonomische Übertragungen und Namensänderungen unter den Algen. Preslia 32: 142-154.

Kofoid, C.A. \& Swezy, O. 1921. The free-living unarmored Dinoflagellata. Memoirs of the University of California 5: $1-562$.

Ohno, N. 1911. Beobachtungen an einer SüsswasserPeridinee. Journal of the College of Science, Imperial University of Tokyo 32: 77-92.

Parke, M. \& Dixon, P.S. 1976. Check-list of British marine algae: third revision. Journal of the Marine Biological Association of the United Kingdom 56: 527-594.

Popovský, J. \& Pfiester, L.A. 1990. Dinophyceae (Dinoflagellida). In: H. Ettl, J. Gerloff \& D. Mollenhauer (eds). Süswasserflora von Mitteleuropa. Gustav Fischer.

Thompson, R.H. 1947. Freshwater Dinoflagellates of Mariland. St Maryl Board of natural Resources 67: 3-24. 